\title{
Comparison of L2- and L1-norm for different nonhyperbolic travel-time approximations
}

Nelson Ricardo Coelho Flores Zuniga (IAG-USP)

Copyright 2021, SBGf - Sociedade Brasileira de Geofísica

This paper was prepared for presentation during the $17^{\text {th }}$ International Congress of the Brazilian Geophysical Society held in Rio de Janeiro, Brazil, 16-19 August 2021.

Contents of this paper were reviewed by the Technical Committee of the $17^{\text {th }}$ International Congress of the Brazilian Geophysical Society and do not necessarily represent any position of the SBGf, its officers or members. Electronic reproduction or storage of any part of this paper for commercial purposes without the written consent of the Brazilian Geophysical Society is prohibited.

\section{Abstract}

The reservoirs of Pre-salt from Santos basin are very complex to be characterized stratigraphically for several reasons. When OBS (Ocean Bottom Stations) technology is used to obtain converted wave events for large offsets, there are three factors together that make the nonhyperbolicity of the event stronger. This difficulty together, with the complex stratigraphic structure, results in a much more complex study to perform a reliable reservoir characterization.

To understand more deeply the accuracy of the nonhyperbolic multiparametric travel-time approximations used to recover the seismic wave velocity information, the comparison of eight approximations for a conventional PP reflected event and for a converted PS reflected event was performed. Furthermore, the comparison of the L2and L1-norm was also performed to understand how the L1-norm can facilitate the optimization during the inversion, aiming to provide a more accurate parameter recovering.

\section{Introduction}

Recently, several comparisons were performed to understand the behaviour and accuracy of nonhyperbolic multiparametric travel-time approximations (Aleixo and Schleicher, 2010; Golikov and Stovas, 2012; Zuniga, 2017 and 2021).

Since Pre-salt conditions and geology are very complex, even though when conventional models from Santos Basin are studied, the necessity of enhance the accuracy is mandatory to perform a better and more efficient stratigraphic characterization. For this reason, to perform the velocity analysis in this work, it is necessary to treat the problem as an inversion procedure according an optimization criterion.

The proposed comparison is capable of providing the approximations which can describe in a better way the kind of geological structure analysed in this work. As it was observed before (Zuniga, 2021), the L1-norm (Least Absolute Deviation) provides a narrower global minimum region, in comparison to L2-norm (Least Mean Squares), which provides a more accurate parameters recovering during the inversion procedure.

In this work, the comparison among several nonhyperbolic multiparametric travel-time approximation for PP and PS reflected events is enriched when the comparison between L2- and L1-norm is performed.

\section{Model}

The Pre-salt model analyzed in this work (Figure 1) is from Santos Basin, and the reservoirs are at more than 5000 meters depth, and the water depth is more than 2000 meters depth.

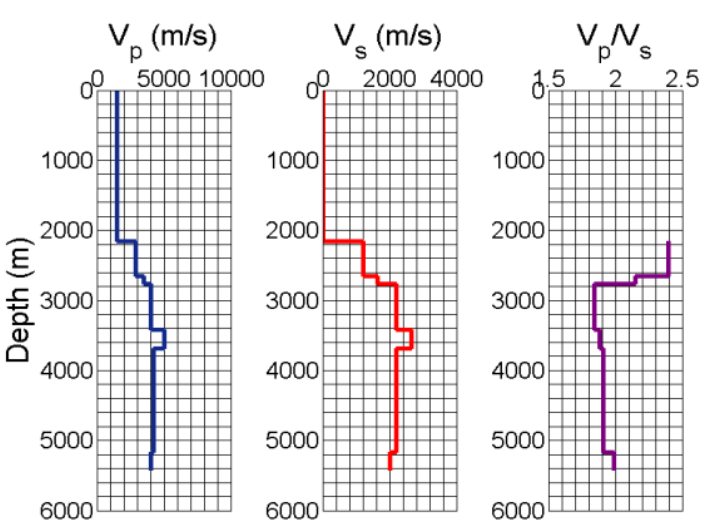

Figure 1: P-wave velocity (Vp), S-wave velocity $(\mathrm{Vs})$ and $\mathrm{Vp} / \mathrm{Vs}$ ratio for the Pre-salt model from Santos Basin.

\section{Method}

To perform the inversion of nonhyperbolic travel-time events, it is necessary to use nonhyperbolic multiparametric approximations able to minimize these effects and recovering the aiming parameters.

The approximations used in this work were described and compared by Zuniga (2017 and 2021) aiming to study the behaviour and accuracy of each one for different geological models. The application of equations used here was strongly studied in previous works (Thomsen, 1986; Castle, 1988 and 1994; Tsvankin and Thomsen, 1994; Li and Yuan, 1999; Tsvankin and Grechka, 2000a 
and 2000b; Fomel and Grechka, 2000 and 2001; Tsvankin, 2001; Yuan and Li, 2002; Li, 2003).

The difference between the observed curve and the calculated one was computed as a percentual travel-time error. With this information, the comparison of accuracy among each approximation, between the PP and PS events, and between the L2- and L1-norm is possible.

Equation 1 - Dix (1955), the hyperbola equation.

$$
t=\sqrt{t_{0}^{2}+\frac{x^{2}}{v^{2}}}
$$

Equation 2 - Malovichko (1978).

$$
t=t_{0}^{2}\left(1-\frac{1}{S}\right)+\frac{1}{S} \sqrt{t_{0}^{2}+\frac{S x^{2}}{v^{2}}}
$$

Equation 3 - Alkhalifah and Tsvankin (1995).

$$
t=\sqrt{t_{0}^{2}+\frac{x^{2}}{v^{2}}-\frac{2 \eta x^{4}}{v^{2}\left[t_{0}^{2} v^{2}+(1+2 \eta) x^{2}\right]}}
$$

Equation 4 - Ursin and Stovas (2006).

$$
t=\sqrt{t_{0}^{2}+\frac{x^{2}}{v^{2}}-\frac{(S-1) x^{4}}{4 v^{4}\left(t_{0}^{2}+\frac{(S-1) x^{2}}{2} \frac{x^{2}}{v^{2}}\right)}}
$$

Equation 5 (Blias, 2009).

$t=\frac{1}{2} \sqrt{t_{0}^{2}+\frac{1-\sqrt{S-1}}{v^{2}}} x^{2}+\frac{1}{2} \sqrt{t_{0}^{2}+\frac{1+\sqrt{S-1}}{v^{2}}} x^{2}$

Equation 6 - Muir and Dellinger (1985).

$$
t=\sqrt{t_{0}^{2}+\frac{x^{2}}{v^{2}}-\frac{f(1-f) x^{4}}{v^{2}\left(v^{2} t_{0}^{2}+f x^{2}\right)}}
$$

Equation 7 - Li and Yuan (2001).

$$
t=\sqrt{t_{0}^{2}+\frac{x^{2}}{v^{2}}-\frac{(\gamma-1)}{\gamma v^{2}} \frac{(\gamma-1) x^{4}}{4 t_{0}^{2} v^{2}+(\gamma-1) x^{2}}}
$$

Equation 8 - Zuniga (2021), the most recently approximation developed, and proposed to be tested for the conditions studied in this work.

$$
t=\sqrt{t_{0}^{2}+\frac{x^{2}}{V^{2}}+\frac{-(\gamma-1)^{2} x^{4}\left(1+\frac{z_{W D} V_{W D}}{t_{0} V^{2}}\right)^{4}}{\gamma V^{2}\left[4 t_{0}^{2} V^{2}+(1-\gamma) x^{2}\left(1+\frac{z_{W D} V_{W D}}{t_{0} V^{2}}\right)^{2}\right]}}
$$

For all the equations tested in this work, $t$ is the traveltime, $x$ is the offsets, $t_{0}$ is the time for zero-offset and $v$ is the velocity of reflected wave. The $S$ parameter is the heterogeneity parameter. The $\eta$ parameter is the one which quantifies the nonhyperbolicity concerning the anisotropy. The $f$ parameter is the anellipitical parameter. The $\gamma$ parameter considers the effects of wave conversion, anisotropy and heterogeneity. For Eq. 8, the $Z_{W D}$ and $V_{W D}$, are a priori parameters, which are, respectively, the water depth and the velocity of the Pwave traveling through the water.

\section{Results}

Figure 2 shows that the Equation 8 is the most accurate, followed by the Equation 7. Equation 1 showed to be the less accurate (as it was expected). Equation 3 and 6 showed to be less significantly less efficient than the other nonhyperbolic multiparametric approximations. Nevertheless, all nonhyperbolic approximations presented an error lower than $1 \%$ for PP event with L2-norm.

For PS event and the same norm (Figure 3), similar results are observed; however, the relative travel-time error increases almost twice for the Figure 2.

The complexity of the two events analysed for the L2norm is strong enough to makes almost no difference for the hyperbola equation. For the other equation, that are adapted to deal with more complex events, the variation of event influences much strongly, since most of them are not proposed to control the nonhyperbolicity related to wave conversion.

Figures 4 and 5 presents the results with L1-norm. In this case, it is possible to observe, for PP event (Figure 4), a very similar behaviour concerning the accuracy of each approximation; the only difference is that the relative travel-time error is significantly lower than the one found with L2-norm.

Figure 5 shows, for PS converted event, the same kind of increase concerning the accuracy when compared to the results for the PS event with L2- norm. 


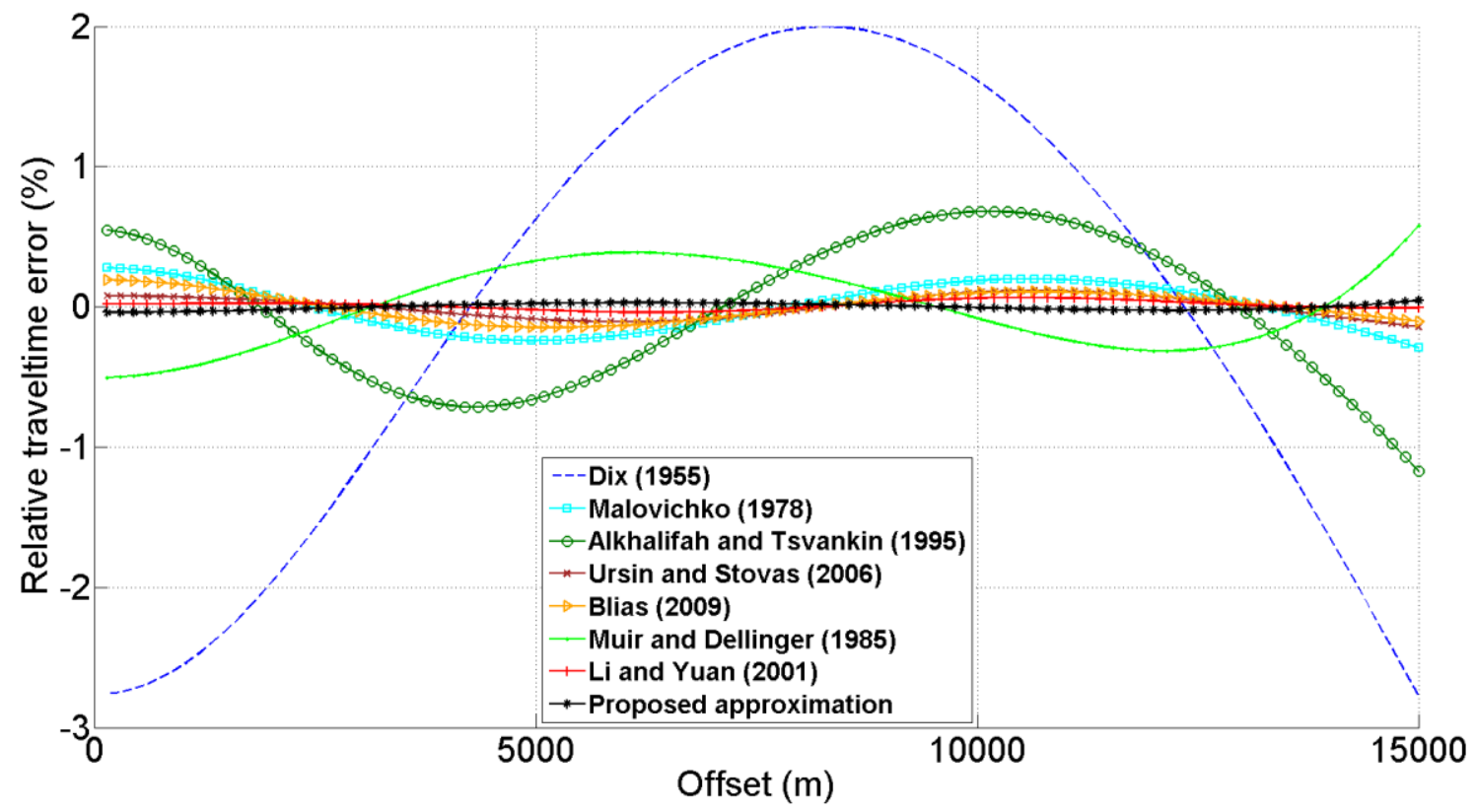

Figure 2: Relative error in travel-time between the observed curve and the calculated curve with each approximation of the $\mathrm{PP}$ reflection event with L2-norm.

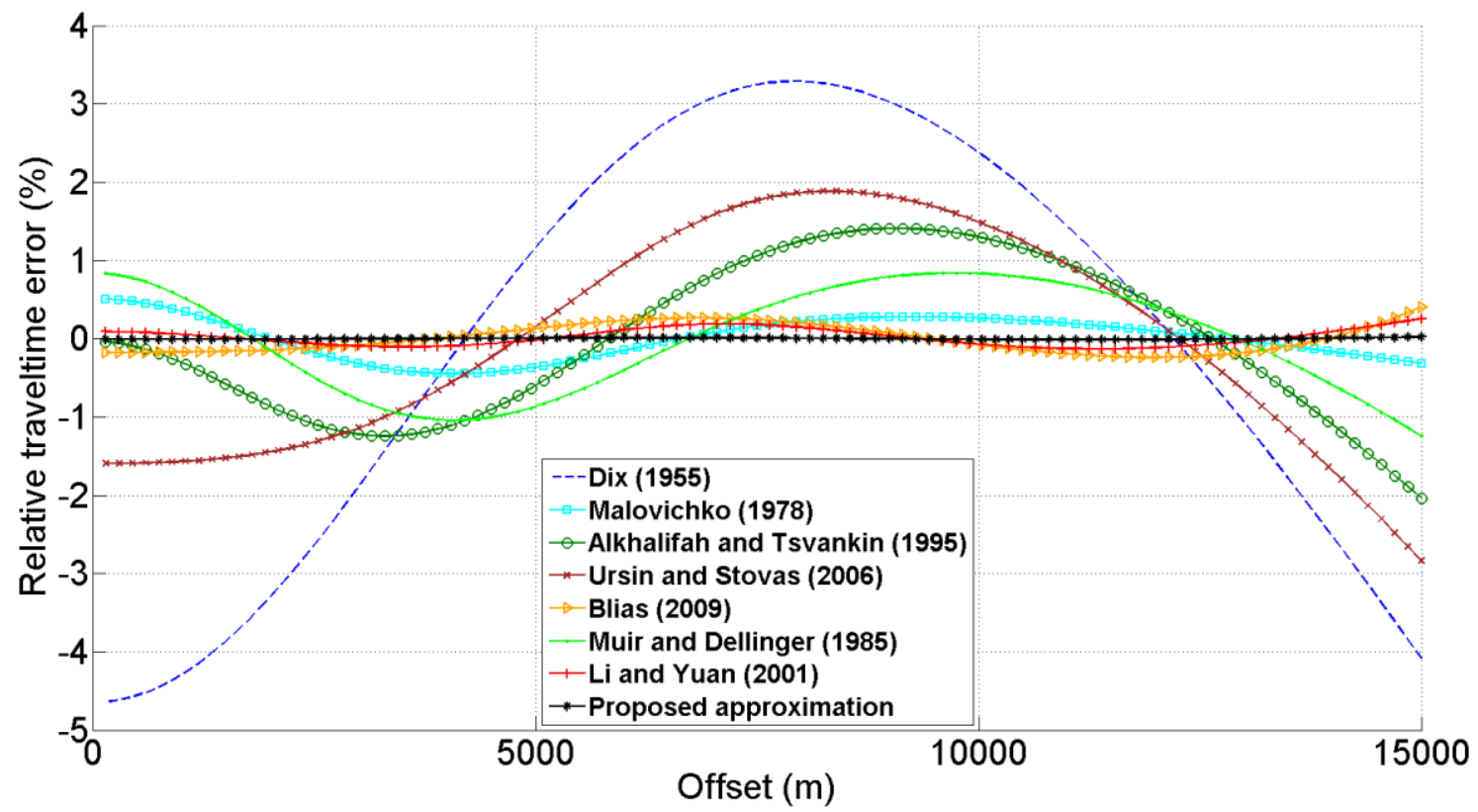

Figure 3: Relative error in travel-time between the observed curve and the calculated curve with each approximation of the PS reflection event with L2-norm. 


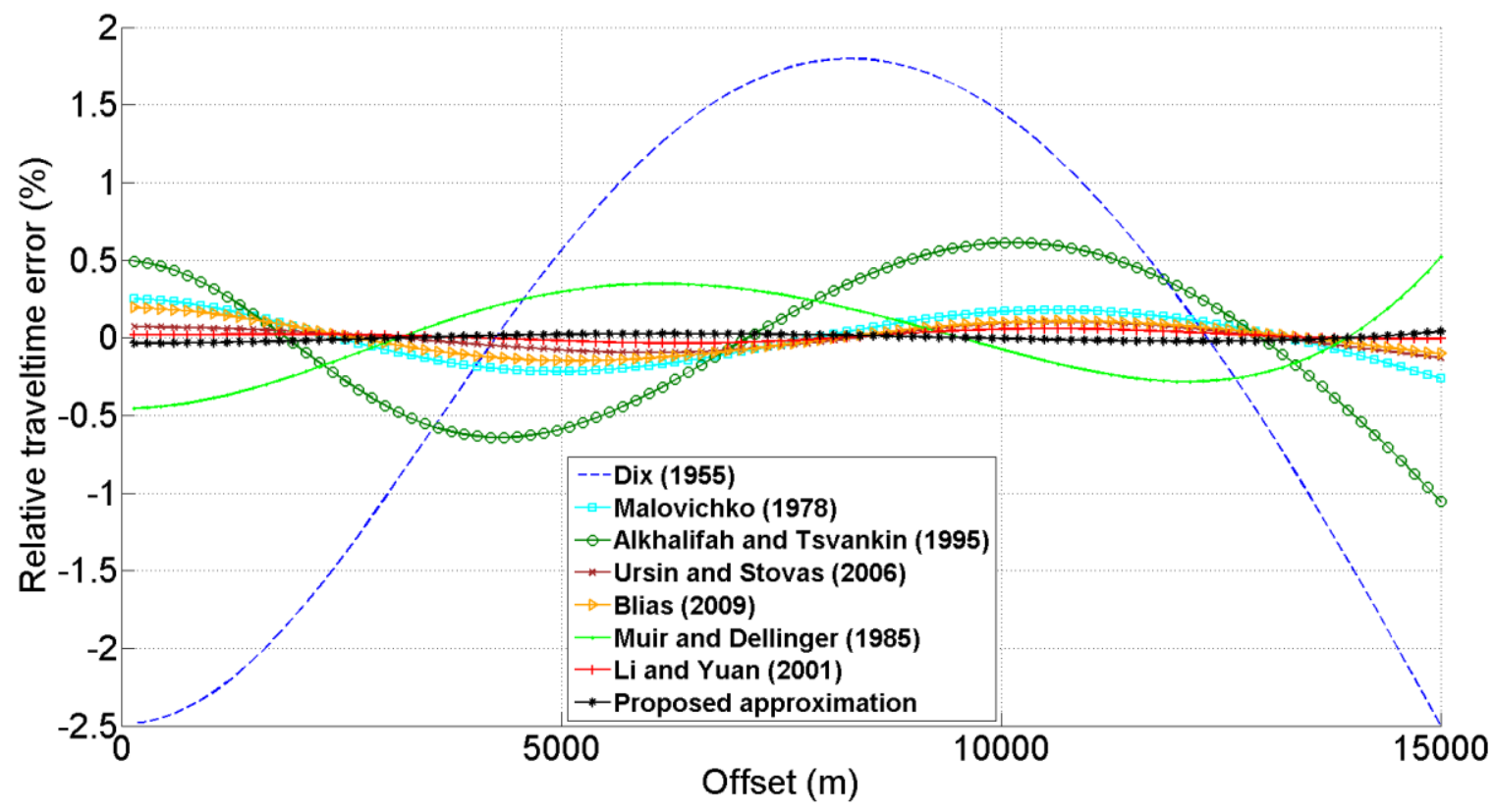

Figure 4: Relative error in travel-time between the observed curve and the calculated curve with each approximation of the $\mathrm{PP}$ reflection event with L1-norm.

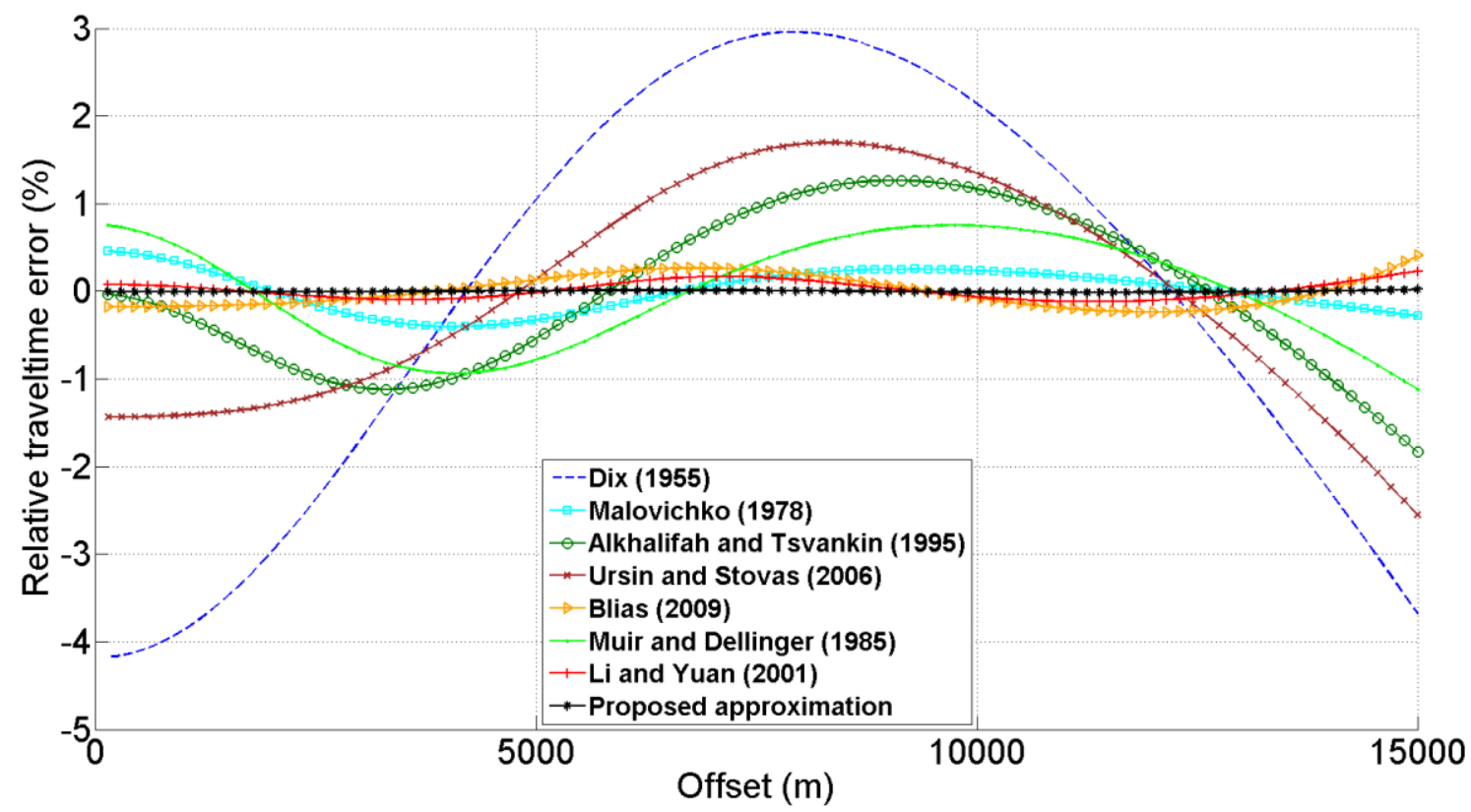

Figure 5: Relative error in travel-time between the observed curve and the calculated curve with each approximation of the $P S$ reflection event with $L 1$-norm. 


\section{Conclusions}

For each equation tested, a decrease of around $11 \%$, concerning the residual travel-time error, was observed when the L1-norm was used.

The equation proposed by Zuniga (2021) showed the best results for this kind of model, for both reflected events (PP and PS), and for both norm functions.

Each other equations showed a significant accuracy enhancement, even though they did not show to be the most accurate for this kind of model. Nevertheless, excepting by the hyperbola equation, each equation showed a travel-time error lower than $2 \%$ for the PS reflected event, and lower than $1 \%$ for the PP event.

\section{References}

ALEIXO, R.; SCHLEICHER, J. Traveltime approximations for $\mathrm{q}-\mathrm{P}$ waves in vertical transversely isotropic media.

Geophys. Prospect.Vol. 58, p. 191-201, 2010.

ALKHALIFAH, T.; TSVANKIN, I. Velocity analysis for transversely isotropic Media. Geophysics, v. 60, p. 1550-1566, 1995.

BLIAS, E. Long-offset NMO approximations for a layered VTI model: Model study. In: 79th Annual International Meeting: Society of Exploration Geophysics, 2009. Expanded Abstract..., 2009.

CASTLE, R. A theory of normal moveout. Geophysics, v. 59, p. 983-999, 1994.

CASTLE, R.J. Shifted hyperbolas and normal moveout. In: 58 th Annual International Meeting: Society of Exploration Geophysics, 1988. Expanded Abstracts..., p. 894-896. 1988.

DIX, C. H. Seismic velocities from surface measurements: Geophysics, 20, p.68-86, 1955.

FOMEL, S.; GRECHKA, V. On nonhyperbolic reflection moveout in anisotropic media. Standford Exploration Project, p.617-640, 2000.

FOMEL, S.; GRECHKA, V. Nonhyperbolic reflection moveout of $P$ waves. An overview and comparison of reason: Colorado School of Report CWP-372, 2001.

GOLIKOV, P.; STOVAS, A. Accuracy comparison of nonhyperbolic moveout approximations for qP-waves in VTI media. Journal of Geophysics and Engineering. Vol. 9, 428-432, 2012.

LI, X. Y.; YUAN, J. Converted-waves moveout and parameter estimation for transverse isotropy. 61st EAGE Conference, Expanded Abstract, v. 1, p. 4-35, 1999.

LI, X.Y.; YUAN, J. Converted wave imaging in inhomogeneous, anisotropic media: Part I. Parameter estimation. In: 63rdEAGE conference, Expanded Abstract, v. 1, p. 109, 2001.
LI, X. Y.; Converted-wave moveout analysis revisited: The search for a standard approach, 73rd Annual internat. Mtg. Soc. Expl. Geophysics, Expanded Abstract, p. 805-808, 2003.

MALOVICHKO, A. A. A new representation of the traveltime curve of reflected waves in horizontally layered media. Applied Geophysics (in Russian), v. 91, n. 1, p. 47-53, 1978.

MUIR, F.; DELLINGER, J. A practical anisotropic system, in SEP-44. Stanford Exploration Project, p. 55-58, 1985.

TSVANKIN, I. Seismic Signatures and analysis of reaction data in anisotropic media. Elsevier, 2001.

TSVANKIN, I.; GRECHKA, V. Dip moveout of converted waves and parameter estimation in transversely isotropic media. Geophysics, v. 48, p. 257-292, 2000a.

TSVANKIN, I.; GRECHKA, V. Two approaches to anisotropic velocity analysis of converted waves. In: 70th Annual Internat. Mtg., Soc. Expl. Expanded Abstrdact, p. 1193-1196, 2000b.

TSVANKIN, I.; THOMSEN, L. Nonhyperbolic reflection moveout in anisotropic media. Geophysics, v. 59, p. 1290-1304, 1994.

URSIN, B.; STOVAS, A. Traveltime approximations for a layered transversely isotropic medium. Geophysics, v. 71, p. 23-33, 2006.

ZUNIGA, N. R. C. F. Análise comparativa de aproximações não-hiperbólicas dos tempos de trânsito de dados sísmicos multicomponente utilizando tecnologia OBN. Master's Thesis, Universidade de São Paulo, São Paulo, 2017.

ZUNIGA, N. R. C. F. Nonhyperbolic multiparametric travel-time approximation for converted-wave and OBN data. PhD Thesis, Universidade de São Paulo, São Paulo, 2021. 